\title{
Native English Teachers in Hong Kong \\ Building Communities of Practice?
}

\author{
Victor Forrester \\ Department of Education Studies, Baptist University \\ Kowloon Tong, Hong Kong (SAR), China \\ Tel: 852-3411-5793Ｅ-mail: vforrest@hkbu.edu.hk \\ Beatrice Lok \\ Faculty of Education, Cambridge University \\ Cambridge, England, United Kingdom \\ E-mail: cybl2@cam.ac.uk
}

\begin{abstract}
A review of the formulation of the Native English Teaching Scheme in Hong Kong is offered establishing its unique characteristics which confound Native English teachers and local schools attaining successful integration. Reporting a three-step exploratory methodology, key elements are identified and operationalised which appear to support successful integration. Discussing these findings in terms of the literature on Induction and Communities of Practice, a case is made that the reported research methodology may be applicable across other integration contexts - where individuals, rather than remaining disengaged 'accidental tourists' seek to become engaged 'agents of change'.
\end{abstract}

Keywords: NETs, Community-of-practice, Hong Kong

\section{Introduction}

In Hong Kong the practice of employing 'native-speaking English teachers' from overseas to teach English in local schools is not new - extending back more than 150 years into the colonial past (Sweeting, 1990) - and is intertwined with changes in the local ideology and sociopolitical development. For example, the earliest lingua-franca English teachers' were missionaries who set-up western-style schools to offset perceived shortcomings of traditional Chinese education (MENET, 2001). The first commercial recruitment of English native speakers - in 1862 by Frederick Stewart, founder of the earliest British style school in Hong Kong, Ying Wa College - also associated the teaching of English with a western-style education (Bickely, 1998). To this end, it is interesting to note that Stewart required those native English speaking staff to acquire at least a working knowledge of Chinese (ibid). Over the subsequent century, the commercial recruitment of English native speakers slowly expanded, peaking in 1963 with 260 expatriates being employed to teach not only English but across all school subjects and all school levels.

In the latter part of the 20th century a shift in both ideology and socio-political development is signaled by a notable decline in the practice of importing native English teachers. By 1982, the term 'localisation' was used to describe the teaching of English in Hong Kong dominated by local teachers - a phenomenon the Review Panel considered as having a negative impact:

'We consider the 'localisation of staffing' policy ought to be amended so that children in their first years of schooling might be exposed to native English speakers, engaged as ancillary staff either on a contract basis or accepted as helpers (e.g. the non-working spouses of British expatriates or other suitable English speakers).'

(Visiting Panel, 1982, III.1.9)

Subsequently, in 1984, the Education Commission Report No.1 echoed the Visiting Panel's recommendation that schools employ 'locally available native English speakers', stopping short of recommending either a systematic or a large-scale recruitment (MENET, 2001). However, in 1986, the Education Department initiated the Expatriate English Language Teachers Pilot Scheme (EELTPS) to be run by the British Council (1989). This pilot scheme - which ran for one academic year from August 1988 to August 1989 - recruited 81 expatriate English language teachers from Britain to work in a representative cross-section of 41 schools with the intention of assessing their impact on both students' language learning and school life (ibid). 
A modified scheme followed in 1989, the Expatriate English Language Teachers Modified Scheme (EELTMS), involving only nineteen schools in the first year of operation and fourteen more schools in the second year (MENET, 2001). Some 33 expatriate English language teachers were employed during the 1989-1990 academic year and 23 in the 1990-1991 academic year (ibid). The Education Department conducted an internal, un-published evaluation of the modified scheme, reporting publicly only that both school directors and the government were happy with the modified scheme (Lo, 1999). This modified scheme continued until the end of the 1996-1997 school year, by which time 87 expatriate teachers were employed.

One features characterizes both the pilot and modified schemes (EELTPS:EELTMS). Both schemes employed teachers on single year, renewable contracts - proving problematic both for recruitment and retention. It is to be noted that whereas in 1963, English speaking teachers were permanently employed across the school spectrum, by the 1980's they were on short-term contracts and only in a relatively few selected schools. Given such terms and conditions, both schemes positioned these teachers less like 'agents of change' and more like 'accidental tourists'.

Whereas the latter part of the $20^{\text {th }}$ century reflected an ideology and sociopolitical development that was content with the 'localisation' of English teaching in Hong Kong, a shift is signaled following the return of sovereignty from Britain to China on July 1, 1997.

Initially the change of sovereignty back to China may have been expected to favour 'localisation' - an expectation strengthened perhaps by the dual decisions first, to end the British Council's role as recruitment-agent; secondly, to implement the compulsory Mother Tongue Education policy in schools (Lai, 1999) which left only 114 secondary schools (ratio 1:3) using English medium of instruction (EMI) schools. Confounding these decisions, the dominant social perception persisted that English language plays an essential role to upward academic, social and career mobility in Hong Kong (Flowerdew, 1998; Johnson, 2001). This social perception additionally raised concerns that the Mother Tongue Education Policy would lead to falling standards of English (Education Commission, 1996), reduce English exposure and quality at CMI schools in comparison to EMI schools (Morrison and Lui, 2000), create unequal access to English (the language of 'power and prestige') between CMI and EMI school students (Choi, 2003) and taint the post-handover image of Hong Kong as an international business center (Lai, 1999). To tackle these problems, the first Policy Address (1997) of the newly formed Hong Kong Government announced the introduction of the Native English Teaching Scheme (hereafter the 'Scheme'). The Scheme empowered the Education Department to launch its first systematic recruitment of overseas native English teachers (hereafter 'NETs').

Under the Scheme, one NET is provided for each government aided secondary school with less than 40 classes - with two NETs provided where the school has 40 or more classes - providing an approximate teacher/pupil ratio of 1:1,000 (Education and Manpower Bureau, 2004). The defined roles of NETs in both Primary and Secondary school settings are the same:

'NETs are required to teach English as a second language to Chinese students and assist in teaching and curriculum development in Government and Government-subvented schools and schools for students with special educational needs.'

(Education and Manpower Bureau, 2006)

\section{Comparison with other Asian schemes}

In Asia, two other countries also import native English speaking teachers to improve their English language education South Korea has its English Program in Korea (EPIK); Japan has its Japan Exchange and Teaching Program (JET) (Carless, 2004; Lee, 2001). Significant differences have been noted between these three schemes (see Ahn et al 1986 for comparison between EPIK and JET; also Lai, 1999 for comparison between JET and NET). Whereas, the Hong Kong Scheme aims at improving both teaching and learning, EPIK only focuses on learning, whereas JET seeks to provide its Western employees with a positive exposure to Japanese culture. Underpinning these significant focal differences is the Hong Kong Scheme's unique pre-employment requirement that NETs must have both relevant teaching experience and language teaching qualifications. When in-post, NETs are expected both to teach English as a second language to students and to support the development of language pedagogy and curriculum. In summary the characteristics of the Hong Kong Scheme differ from EPIK and JET in terms of the recruits' prior teaching experience, minimum qualifications and their expected teaching roles and responsibilities.

\section{Summation of the Scheme's formulation}

From a sociopolitical perspective, the Scheme and its predecessors - ranging from the earliest missionaries to the EELTPS in 1986 - may be seen as a socially-driven reaction against the perceived shortcomings of a predominantly Chinese education system. The center of this social reaction is a two-way concern about access to the benefits of Western/Chinese markets while its antidote is consistently founded in providing an - albeit limited - supply of 'native speakers' responsible for instilling more than language teaching. In a competitive market-place, limited supply leads to higher valuations while socially, higher valuations then leads to higher expectations - a formulae exemplified in 1997 by 
the implementation of the Mother Tongue Education policy and the introduction of the Scheme which, unlike other Asian schemes (EPIK; JET), is formulated with high expectations that 'native speakers' will enhance not only the English proficiency level of students but also to provide professional support to the local teachers of English.

\section{Implications of the Scheme's formulation}

The uniqueness of the Scheme reflects the social factors that led to its formulation. This historical legacy places high expectations on newly recruited NETs who, unfamiliar with the local educational context, are sited as 'agents of change', held responsible not only for effective classroom English language teaching but also for developing local English teachers' pedagogy. Adding to this burden, NETs are most commonly allocated to schools in isolation - with little or no reference initially to the broader or prior NET-experience. From the individual NET perspective this siting can engender an early experience less of being an 'agent of change' and more of being 'an accidental tourist' unfamiliar with the individual School community. The situation is no less clear from the school community perspective. Whereas the popular 'social perspective' may endorse the value of acquiring a school-based 'native speakers', their professional school-based role is problematic - local teachers of English may feel their professionalism slighted; school-based administration which traditionally values local experience, may find difficulty in 'locating' NET expertise; pupils accustomed to exam-targeted learning may be confused by NETs' alternative learning focus; parents may feel unease if placed in face-to-face communication with a NET. Over-riding all such issues, is a Government policy - responding to strong social reaction that has to be followed.

Based on the issues raised by the Scheme's formulation, we now turn to consider the challenges facing the Scheme's implementation.

\section{Implementation of the Scheme}

The aims of the Scheme embrace the improvement in Hong Kong of both the learning and teaching of English. Studies of the respective merits of native and local English teachers are well established (Medgyes 1992: Tang, 1997; Barrat et al, 2000) leading recent reviews of the Scheme's implementation to further develop this pedagogic focus (Carless, 2006). However, the aims of the Scheme are broad and place NETs as being held responsible across an impressive array of expectations - both for classroom teaching, for extra-curricular English activities (such as English drama and English debate), developing good teaching methods, preparing and developing teaching materials, and to aid in the professional development of teaching staff (Lok, 2004).

Given the comprehensive range of the Scheme's aims - embracing improvements across the spectrum of learning and teaching at both Primary and Secondary school levels - it is perhaps predictable that the Scheme's implementation should prove problematical. As a government-sponsored antidote to a strong social reaction, it is perhaps equally predictable that government-sponsored public evaluations of the Scheme should seek to be positive.

\section{Review of the Scheme's evaluation reports}

Publicly, the government has asserted that the Scheme brought about a professional development in English teaching (Policy Address, 2001), claiming that NETs facilitate not only the development of English teaching at school, but also of the design and planning of the school curriculum. In contrast, an unpublished government-sponsored report (Storey et al 2001) is cited as reporting that 'at the secondary level there was a lack of genuine collaboration . . . little shared understanding or common philosophy' (Carless et al, 2006). Other published reports have criticized NETs for 'not understanding the weaknesses and difficulties Chinese people have in learning English' and for 'failing to understand the syllabuses of Hong Kong public examinations as they were not familiar with the local education context' (Lung, 1999, Lu and Wong, 2002). NETs unfamiliarity with the local education context is a theme that re-echoes across both time and in reports from both Primary and Secondary sectors - Griffin et. al, (2005; 2004): Lok (2002): MENET (2001); Lo (1999), British Council (1989).

By definition, NETs may expect to face both language and cultural differences when interacting with local English teachers - challenges known to be problematical when negotiating their own identity within the school community (McAllister and Irvine, 2000). However, successful integration with the school community is essential if NETs are to implement the aims of the Scheme (Little, 2002). Benefits accruing from integration within a school community are well recognized - including improving teaching and learning, empowering teachers collectively to question ineffective teaching practices and school structures, developing innovative pedagogy and curriculum, and engaging actively in supporting professional growth (see respectively: Achinstein, 2002; Grossman et al, 2001; Witiziers, et. al, 1999 and Strokes, 2001). Accordingly, successful NET integration not only would enhance pupil learning, but also empower both NET and local English teachers to professionally develop (Wilson and Berne, 1999).

Given the significance of successful NET integration it is helpful here to review what constitutes successful integration.

\section{Methodology and Empirical Analysis}

To explore the conceptual and practical needs of NETs working in local schools we report a three-step exploratory research methodology: 
7.1 First we analyse one case study to understand more clearly the notion of successful NET integration in a Hong Kong school.

7.2 We then compare emergent key factors with data from NETs seeking integration help.

7.3 From this comparison we construct and report on an exploratory intervention Workshop aimed at promoting 'successful integration'.

\section{1 the Notion of Successful NET Integration in a Hong Kong Secondary School}

To understand more clearly the notion of successful NET integration, a case-study was conducted in July 2006 of one school recognised as a good example of successful NET integration by both the Education and Manpower Bureau and the Native English Speaking Teachers Association. The school is co-educational, secondary, founded in 1996, with two NETs. To understand the notion of successful NET integration we interviewed both the NETs (N1 and N2) and the English Panel Chair (P1).

N1, employed as a teacher mentor, has a doctorate in Education, is in her first year of teaching in Hong Kong, and previously taught in her home country, United States, for fifteen years in secondary school settings and ten additional years in teaching training. N2 teaches regular English lessons, is post-graduate teaching qualified, likewise is in his first year of teaching experience in Hong Kong, and has taught in Japan and previously in New Zealand for 20 years. Their Panel Chair (P1) has a Masters degree and has been teaching in Hong Kong for sixteen years. In summary, all interviewees are professionally trained with at least 15 years of school-based teaching experience.

An analysis of our pilot research interview data, identifies five key factors that here contribute to successful NET integration.

First, to be a successful NET, for N2, is the ability 'to accept': including being flexible, patient and tolerant, having the ability to be easy and not getting too upset about things in work. For N1, she identifies the importance of being 'accepted': 'I don't feel that they look down on me, although I look different and think different from them, I still feel accepted.'

Second, both NETs voice a strong sense of satisfaction, confidence in their teaching and professional growth - endorsed by their P1 who noted that the English classes taught by N2 obtained the best Hong Kong Advanced Level Examination (HKALE) results of the School, and that over $80 \%$ of the students passed their English subject in HKALE.

Third, both N1, N2 and their PI agreed on the importance of good communication - expressed by N1 as: 'I think a lot of that (successful NET integration) has to do with communication... this school has been wonderful in that, the Panel Chair includes us in everything, tells us what is going on, has meetings in English...I think that helps a lot.'

Fourth, for N2: 'it is important to ensure all parties are satisfied with what is asked and given'. Elaborating, N1 noted: 'we (English) teachers all work together well as a team, partly has to do with our Panel Chair, she developed that and she also makes sure that we all have a chance to co-teach together...' For their P1 she noted the importance of understanding both NETs' uniqueness and their need to understand the culture of the school.

Fifth, it is to be noted that access to the three interviewees was made possible only by the kind permission of the PI. Access to the school's local teachers of English was requested, but politely rejected on grounds both of 'work-load' and that the PI would fairly present their views. As an initial characteristic of this school's 'community of practice', this observation highlights a final key factor - that of accepting administrative control.

In summary, five key social interactions emerge from our 'successful NET integration' case study:

accepting and being accepted;

being a teaching professional;

using formal and informal communication,

engendering a good working relationship

accepting administrative authority.

To explore whether or not these five key social interactions inform another context we now compare these key factors with data from NETs seeking integration help.

\subsection{NETs Seeking Help: Background}

Voluntary NET respondents were drawn from across a spectrum of educational settings. The background of these NETs seeking help is displayed in Table 1. 
Table 1. NETs seeking help: Background

\begin{tabular}{|l|l|l|l|l|l|l|l|l|l|l|l|l|l|l|}
\hline Organisation & $\begin{array}{l}\text { Education and } \\
\text { Manpower Bureau }\end{array}$ & $\begin{array}{l}\text { NETs in } \\
\text { School Settings }\end{array}$ & $\begin{array}{l}\text { NETs in Secondary School } \\
\text { Settings }\end{array}$ \\
\hline $\begin{array}{l}\text { No. of Participants } \\
\text { Gender }\end{array}$ & 2 & 3 & Female & Male & Female \\
\hline No. of Participants & Male & Female & Male & 1 & 1 & 2 & 3 & 4 \\
\hline
\end{tabular}

As displayed above, our respondents are drawn from across the NETS spectrum including gendered representation from both EMB, Primary and Secondary sectors.

To record their perceived needs, respondents completed a pre-Workshop open-ended questionnaire eliciting views on their NET teaching experience, issues they would like to discuss \& help they would like to receive.

Findings indicated the complexity of being a NET in Hong Kong schools. Of the eleven respondents, six described their teaching experience as neutral and five described it as a negative experience. Illustrative voices include:

'I have learnt a lot from being a NET in Hong Kong about a different culture and approach to things and about myself.' (Respondent 1)

'The Hong Kong primary school system is 50 years behind the west. It is like being a time traveler.' (Respondent 2)

'Despite my school being open to new ideas, it's still far from what I thought I'd be doing.' (Respondent 3)

They also raised a range of issues and requests for diverse forms of help - as displayed in Table 2:

Table 2. Respondents’ Issues \& Help Requested

\begin{tabular}{|l|l|}
\hline Issues raised & Frequency \\
\hline a) The role of the NET & 4 \\
\hline b) Making changes to the current system & 3 \\
\hline c) Knowing more about Local English Teachers & 3 \\
\hline d) ELT Pedagogy & 3 \\
\hline e) Communicating with colleagues & 3 \\
\hline f) Administration \& Management & 2 \\
\hline g) Strengths of being a NET & 2 \\
\hline Help requested & 2 \\
\hline h) Sharing Experiences and finding solutions & 4 \\
\hline i) NET Contacts & 2 \\
\hline j) Adaptation & 2 \\
\hline
\end{tabular}

Marginally the most frequent issue of concern was the role of the NET $(f=4)$. Respondents however were also concerned about $(\mathrm{f}=3)$ their expected 'change' role within the current education system; the training of Local English teachers' (LETS); current Hong Kong English teaching pedagogy and how to develop current levels of communication with their school colleagues. Other issues included understanding local school management practices and the local perceived strengths of being a NET.

Notably, the help requested by these respondents is directed towards two communities of practice. From their peer NET community they seek specific knowledge sharing - of teaching experiences, practices and solutions. From their local school community they struggle to conceptualise effective modes of discourse - as illustrated below:

'be flexible and ready to adapt . . . introduce ideas . . gradually and with sensitivity.' (Respondent 4)

'be very open minded and tolerant beyond belief' (Respondent 5)

Respondents' struggle to conceptualise effective modes of school-community discourse leads to an underlying frustration when working as a NET in school - a frustration that both raises self-doubts and doubts about the Scheme as expressed ironically in the response 'Being a successful NET...do I win a chocolate bar?' 
Having reported the help NET's seek how do these findings compare with our case-study analysis of 'successful integration'?

It is interesting to note the close similarities between being a successful NET - as narrated by our respondents - and those reported from our case-study. For example, both exemplify key roles for accepting and being accepted (Respondent 1); being a teaching professional (Respondent 5); formal and informal communication (Respondent 4), developing a good working relationship (Respondent 3) and accepting administrative control (Respondent 2).

From this comparison, it seems that although many of our questionnaire respondents may recognise elements of being a successful NET in Hong Kong, operationalising those elements appears difficult and problematic.

How to operationalising key elements of 'successful integration' leads us now to report an exploratory NET Integration Workshop.

\subsection{An Exploratory NET Integration Workshop}

An exploratory workshop was held half-way through the local schools' first term (November, 2006) when teachers generally are more settled into the school year and have these experiences to share and discuss.

Workshop participants comprised the same respondents to our initial questionnaire - whose background details are displayed in Table 1.

The Workshop Matrix (Table 3) aligns the expectations of the participants, the key features of our case-study of 'successful integration' and the workshop content.

Table 3. Workshop Matrix

\begin{tabular}{|c|c|c|c|}
\hline $\begin{array}{l}\text { Workshop Thematic } \\
\text { Session }\end{array}$ & $\begin{array}{l}\text { Workshop Content \& } \\
\text { Sequence }\end{array}$ & $\begin{array}{l}\text { Respondents' } \\
\text { Questionnaire Issues }\end{array}$ & $\begin{array}{l}\text { Case-study Interview } \\
\text { Findings }\end{array}$ \\
\hline \multirow{3}{*}{$\begin{array}{l}\text { 1. Hong Kong school } \\
\text { system, education reform } \\
\text { and the local teaching } \\
\text { context }\end{array}$} & $\begin{array}{l}\text { A review of the current } \\
\text { Hong Kong education } \\
\text { reform }\end{array}$ & $\begin{array}{l}\text { c) Knowing more about } \\
\text { Local English Teachers }\end{array}$ & \multirow[t]{3}{*}{$\begin{array}{l}\text { 'To accept ... and be } \\
\text { accepted' }\end{array}$} \\
\hline & $\begin{array}{l}\text { Empirical studies of the } \\
\text { challenges faced by a local } \\
\text { beginning teacher }\end{array}$ & $\begin{array}{l}\text { e) Communicating with } \\
\text { colleagues }\end{array}$ & \\
\hline & $\begin{array}{l}\text { Teaching Education in } \\
\text { Hong Kong and its } \\
\text { implication for NETs }\end{array}$ & j) Adaptation & \\
\hline \multirow{3}{*}{$\begin{array}{l}\text { 2. English language } \\
\text { teaching strategies in Hong } \\
\text { Kong classroom }\end{array}$} & $\begin{array}{l}\text { Classroom situation in } \\
\text { Hong Kong }\end{array}$ & d) ELT pedagogy & $\begin{array}{l}\text { 'Being a } \\
\text { Professional' }\end{array}$ \\
\hline & $\begin{array}{l}\text { Teachers' perception of } \\
\text { students reticence }\end{array}$ & $\begin{array}{l}\text { h) Sharing Experience and } \\
\text { finding solutions }\end{array}$ & \\
\hline & $\begin{array}{l}\text { Teaching Strategies in the } \\
\text { classroom }\end{array}$ & & \\
\hline \multirow[t]{4}{*}{$\begin{array}{l}\text { 3. NET integration with } \\
\text { Schools \& students. }\end{array}$} & $\begin{array}{l}\text { Multiple identities of } \\
\text { being a NET in Hong } \\
\text { Kong }\end{array}$ & a) The role of NET & \multirow[t]{4}{*}{$\begin{array}{l}\text { 'Formal and informal } \\
\text { Communication' }\end{array}$} \\
\hline & $\begin{array}{l}\text { NET integration with the } \\
\text { school and classroom }\end{array}$ & $\begin{array}{l}\text { g) Strengths of being a } \\
\text { NET }\end{array}$ & \\
\hline & $\begin{array}{l}\text { Access to the community } \\
\text { of practice }\end{array}$ & $\begin{array}{l}\text { e) Communicating with } \\
\text { colleagues }\end{array}$ & \\
\hline & $\begin{array}{l}\text { Preparation for being a } \\
\text { change agent }\end{array}$ & $\begin{array}{l}\text { b) Making a change to the } \\
\text { current system }\end{array}$ & \\
\hline
\end{tabular}

The above Workshop Matrix aligns the findings of our interview case-study with those issues raised by our questionnaire respondents (see Table 2). This alignment resulted in three thematic Workshop Sessions and related content (respectively columns 1\&2). Comparing columns 1 and 4 displays the alignment of each of the three thematic Workshop Sessions with 
our case-study interview findings. Comparing columns 2 and 3 displays the alignment of our Workshop content with respondents' questionnaire responses.

For example, Thematic Session 1 'Hong Kong school system, education reform and the local teaching context' provided participants with three sub-topics, each of which aligns with respondents' questionnaire topics (see: Table 2). Specifically, 'a review of the current Hong Kong education reform' aligns with the participants' questionnaire topic c) 'knowing more about local English teachers'; the Workshop topic 'empirical studies of the challenges faced by a local beginning teacher' aligns with the participants' questionnaire topic e) 'communicating with colleagues', while the third Workshop topic 'teaching education in Hong Kong and its implication for NETs' aligns with the participants' questionnaire topic j) 'adaptation'.

Additionally, Table 3 displays that the Workshop matrix alignment also embraces the findings of the case-study interviews on successful NET integration. For example the case-study finding 'To accept and be accepted' aligns both with the content and Workshop theme 1) 'Background information of Hong Kong school system, its education reform and the local teaching context'. This alignment continues across the remaining two Workshop thematic sessions.

Explicitly absent from the Workshop matrix are two case-study findings - however these items are held to be implicitly operationalised within the context of a Workshop. Specifically, 'Good working relationship' is implicit in being an active Workshop participant while 'Acceptance of Administrative authority' is implicit in both voluntarily joining a Workshop and working within the Workshop's agenda.

\subsubsection{Evaluation of the Workshop}

Workshop participants completed a closed and open-ended Workshop evaluation questionnaire. The questionnaire comprised two parts: 1) General evaluation scaled against a five-point Likart scale where 1 means strongly disagree and 5 means strongly agree, and 2) Feedback on specific areas.

\section{Part 1: General Evaluation}

All participants were satisfied with the contents of the workshop (mean=4.33) and its organization (mean=4.78). Over $80 \%$ of participants agreed that they would recommend the workshop to others and would like to attend similar workshops again in future, with a mean value of 4.22 and 4.33 respectively.

\section{Part 2: Feedback on specific areas}

Feedback on the Workshop's three thematic sessions suggested two improvements: more discussion between participants and more in-depth discussion about the teaching strategies and the relationship between NET and local teachers.

\section{Discussion}

In Hong Kong, provision is made by both the Education and Manpower Bureau (EMB) and the Hong Kong Institute of Education (HKIED) for all new NETs to attend a series of Induction programmes - a provision reasonably clearly justified in the literature 'not only for new teachers ... (but also) for those who change roles' (Draper et al 2006) for 'the move to a new (context) throws into question the existing professional self and raises questions about coping' (Kelchtermanns, 1993). Such self-questioning is understood to stem from a recognition that 'learning is embedded in its context' (Lave et al, 1991) and that good teaching recognizes 'it is important to understand the setting ... and to build on it' (Tickle, 2000). Specifically, good Induction recognizes 'that teachers . . . come with considerable work experience (for whom) induction may be learning about working in schools as a teacher." (Gatherer, 2003) for induction addresses 'the link between teaching and identity' (Ball, 2003).

However, by definition, induction is an initial step and, despite an extended induction programme, our review of the Scheme's evaluation reports consistently point to issues of failed integration. To understand and remedy this problem of failed integration, we reported an exploratory NET Integration Workshop, which sought to operationalise five elements identified in a reported case-study which were then aligned with respondents' questionnaire responses.

Participant evaluations of this Workshop were strongly positive - indicating perhaps that our focus on aligning elements from a 'successful' case-study with their own needs as reported identified in their questionnaire findings, is meaningful to these participants. However our Workshop feedback also indicated participants' desired more discussion opportunities both between participants and on the 'coping' areas of teaching strategies and school-based relationships.

A further apparent weakness of our Workshop include the limitations of our findings for our Workshop focuses only on the NET perspective, has a small number of participants and is context-specific. Such limitations would normally invalidate the findings' generalisability. However these limitations do not detract from these findings illuminating the possibility of identifying and then operationalising key elements across contextually similar 'communities of practice'.

To understand further how to operationalise successful NET integration, we turn now to discuss our findings in the light of the literature on 'community of practice' 
Initially, communities of practice 'received attention in the early 1990's when it was observed that learning takes place through informal social interaction anchored in the context of problem solving' (Brown et al 1991). This observation places the formation of communities of practice as a pragmatic social response or shared need to 'problem solve' - such as posed by the Scheme's problematic formulation and a Government Policy that mandates school communities and NETs to work together.

Subsequent research indicates that communities of practice address their 'problem solving' in a variety of informal ways e.g. through natural social interaction (Orr, 1996); group meetings and notes (Wenger 1998) and so provide a variety of organizational benefits e.g. increasing both performance (Lesser and Storck, 2001), competitive advantage (Teigland, 2000; Liedtka, 2000) and by supporting the sharing of knowledge (Fontaine and Millen, 2002). A simmilar link between organizational benefits and 'informal ways' of communication is also apparent in our data - reflected both in the reported interview and questionnaire findings (Table 3) such as, respectively, 'formal and informal communication' and 'communicating with colleagues'. The Workshop evaluation equally reflects this link between organizational benefits and 'informal ways' of communication where participants noted a desire for more on-going discussion, beyond the formal structure of the Workshop - indicating perhaps their summative conclusion that building 'communities of practice' is not a one-shot affair.

Reflecting an evolving understanding, definitions of 'community of practice' have also evolved:

'(Community of practice) is, in its essence, a fundamentally social phenomenon, reflecting our own deeply social nature as a human being’. (Wenger, 1998)

'A community of practice is . . matrix management done right . . focusing not on reporting relationships but on knowledge, competence and innovation'. (Wenger at al, 2002)

'Community practice is the application of practice skills to alter the behavioral patterns of community groups, organizations and institutions or people's relationships and interactions with these entities.' (Hardcastle et al, 2004)

'The concept of 'communities of practice' has become an influential one in education . . . (embracing) issues around conflict, power and the significance of the broader social context . . ' (Barton et al, 2005)

The above definitions of 'communities of practice' indicate that, essential to successful community-building and in particular here, successful NET integration, is the support given to how people interact.

Of particular relevance to our understanding of the problems facing the Scheme's implementation is the observation by Blacker et al (2000):

'knowledge sharing (between communities of practice) is a relatively neglected topic . . and is likely to be more complex than intra-community knowledge sharing, due to the lack of shared consensual knowledge or shared sense of identity... . the development of trust (i.e. developing social relationships) is seen to be a key . . before effective

knowledge sharing can occur ... (for) the shared infrastructure of . . cooperation within particular communities ... can act as a barrier to close collaboration with outsiders'

From our review of the Scheme's formulation, it is clear that NETs are expected to enact 'knowledge sharing' between a range of communities of practice - with pupils, local teachers of English and the broader School community. However, as our review of the Scheme's evaluation reports indicates, NET's are to achieve this 'knowledge sharing' despite being sited in school contexts that may lack the necessary 'cooperation within particular communities' and that this lack of 'cooperation' may engender 'a barrier to close collaboration with outsiders'.

To help resolve such barriers, the methodology of our reported Workshop may be helpful. This methodology first identified key features of one successful 'community of practice'; then the issues and needs of NETs 'seeking help' and third, aligned these two findings to generate a Workshop Matrix (Table 3). In this Workshop Matrix - unlike the common practice of Induction programmes - the focus was not on 'reporting' but rather on the community of practice elements of sharing 'knowledge, competence and innovation' (Wenger at al, 2002). From this community of practice perspective, our reported findings do not seek to produce generalizations but rather a methodological illustration which may be applicable to other contexts.

Although the notion of communities of practice provides both a useful analysis and a possible methodological intervention, there are acknowledged limitations. For instance, the current development of the concept fails to take into account both the power and the dynamics of the relationships among different practitioners in different communities of practice (Gee, 2005). Accordingly, future research may seek to incorporate such dynamics - as suggested by Keating's (2005) activity theoretical approach - to explore how practitioners may be restrained, mediated and yet still introduce change within specific social structures. 


\section{Conclusion}

The formulation of the Native English Teaching Scheme (Scheme) in Hong Kong has been reviewed in terms of problematising the integration of expatriate teachers of English (NETs) within Hong Kong schools' 'communities of practice'. A review of a series of exploratory research projects were then reported - case-study interviews; questionnaire data and a Workshop. These findings were then reviewed both in terms of the literature on Induction and that of 'communities of practice'. This review highlighted a limitation of 'induction' to help NETs successful integration rather, a case was made for viewing our findings and methodology as illustrative of the workings of a successful 'community of practice'. The 'community of practice' perspective is held to be significant for it appears to have the potential to help move NETs from being 'accidental tourists' who feel largely disengaged from their school communities, to fulfilling the Scheme's aim of fully engaged NETs capable of acting as 'agents of change'.

\section{References}

Achinstein, B. (2002). Community, diversity and conflict among schoolteachers: the ties that blind. New York: Teachers College Press

Barton, D. and Tusting, K.(eds) (2005). Beyond Communities of Practice: Language, Power and Social Context. Cambridge University Press.

Bickely, G. (1998). A Response to the Book Review. Asia Pacific Journal of Language in Education, 1:2, pp. 151-153.

Education Convergence. (1999). Education Convergence: The First Report on the Questionnaire of the NET Scheme http://www.edconvergence.org.hk/studyNsurvey/NET992.html (Retrieved 21 November 2005)

Education and Manpower Bureau (28 November 2006) NET Scheme in Secondary Schools http://www.emb.gov.hk/index.aspx?langno=1\&nodeid=1254

Gee, J.P. (2005). Semiotic social spaces and affinity spaces from the Age of Mythology to today's schools. In Barton, D. and Tusting, K.(eds) Beyond Communities of Practice: Language, Power and Social Context (pp.105-138). Cambridge University Press.

Keating, M.C. (2005). The person in the doing: negotiating the experience of self. In Barton, D. and Tusting, K.(eds) Beyond Communities of Practice: Language, Power and Social Context (pp.105-138). Cambridge University Press.

Lok C.Y.B. (2004). The NET Scheme and Pupils with Low English Proficiency: A Case-study in a Hong Kong Secondary School. Cambridge: University of Cambridge (Unpublished M.Phil Thesis).

Lok, C.Y.B. (2002). Pedagogical Differences between Native and Non-native English Teachers in Hong Kong Secondary Schools. York: University of York (Unpublished M.A. Thesis).

MENET. The Hong Kong Institute of Education. (2001). Monitoring and Evaluation of the Native-speaking English Teacher Scheme: Technical Report, Hong Kong: The Hong Kong Institute of Education. 